\title{
A Era Lula e sua questão econômica principal \\ crescimento, mercado interno e distribuição de renda
}

\author{
André M. Biancarelli ${ }^{1}$
}

\section{Resumo}

O presente texto procura jogar luz sobre o que se julga ser a característica distintiva da Era Lula em termos econômicos: uma maior sintonia entre objetivos econômicos e sociais. A hipótese com a qual se trabalha é a de que o conteúdo social do desenvolvimento brasileiro, ensaiado na Era Lula, é não apenas defensável do ponto de vista moral, como também se mostra a melhor alternativa econômica diante das dificuldades e limitações enfrentadas pelo Brasil atualmente. As seções do texto tratam, na sequencia, do contexto histórico a envolver essas questões; dos bons resultados do governo Lula (20032010); das dificuldades e reações no mandato de Dilma (pós-2011) e, por fim, de algumas ideias e prioridades para renovar e aprofundar este "social-desenvolvimentismo".

\section{Palavras-chave}

Era Lula, estratégia de desenvolvimento, crescimento, justiça social.

Recebido em 12 de novembro de 2013

Aprovado em 4 de fevereiro de 2014

BIANCARELLI, André M. A Era Lula e sua questão econômica principal: crescimento, mercado interno e distribuição de renda. Revista do Instituto de Estudos Brasileiros, Brasil, n. 58, p. 263-288, 2014.

D0I: http://dx.doi.org/10.11606/issn.2316-901X.v0i58p263-288

1 Universidade Estadual de Campinas (Unicamp, Campinas, SP, Brasil). 


\title{
Lula's Era and its Main Economic Question Growth, Domestic Market and Income Distribution
}

\author{
André M. Biancarelli
}

\section{Abstract}

The goal of this paper is to discuss the distinctive aspect of Lula's Era in economic issues: the positive interactions between social and economic dimensions. The central hypothesis is that the social side of recent development strategy is defensible not only in moral grounds, but also is the best option in the difficult current context. The sections of the text are dedicated to discuss: the historical background; the transformations and the positive numbers during Lula's mandate (2003-2010); the worse performance and major challenges faced by Dilma's government (since 2011) and, finally, some ideas and priorities to renew and deepen this "social-developmentalism".

Keywords

Lula's Era, development strategy, economic growth, social justice. 


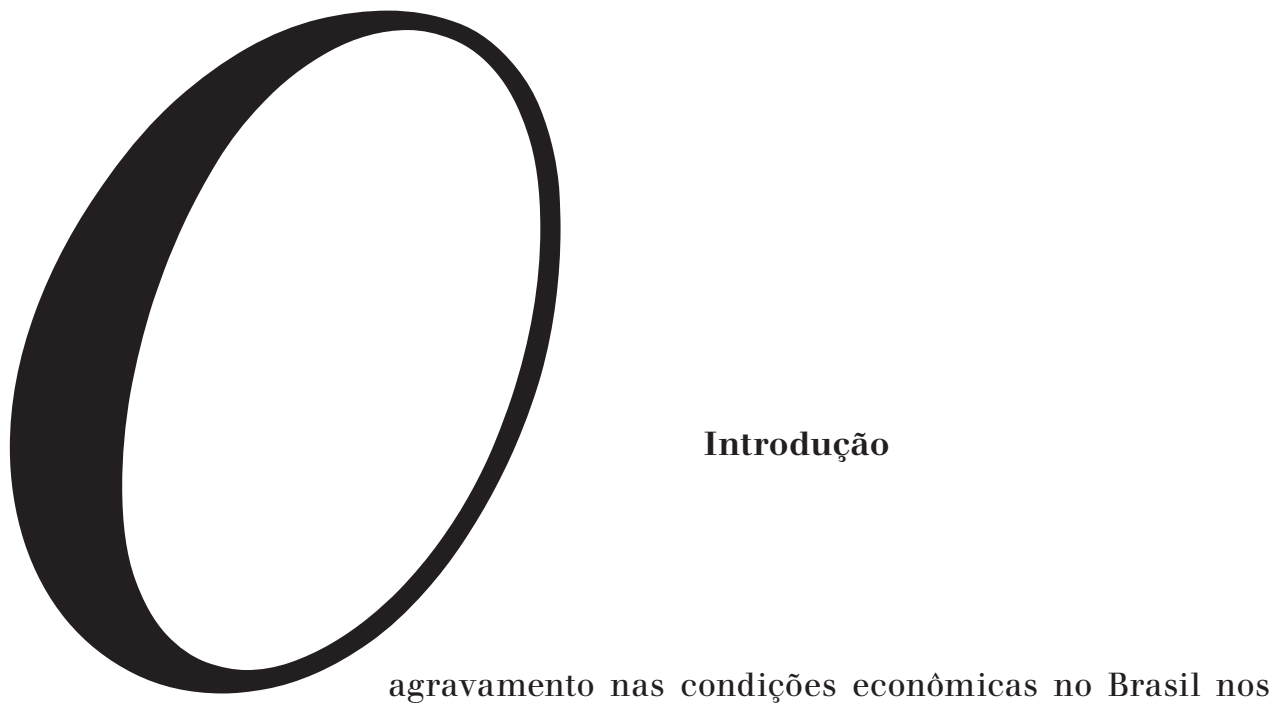
anos de 2012 e 2013 - em termos de taxas de crescimento, inflação, contas externas e contas públicas - ainda que longe de justificar o alarmismo reinante, revela um acentuado contraste com o otimismo do final do governo Lula (2003-2010). Também impulsionado pela onda de protestos que tomou conta das grandes cidades brasileiras em junho de 2013, e inevitavelmente sofrendo as influências da eleição presidencial marcada para outubro de 2014, o debate tem sido marcado por uma série de balanços críticos sobre a "Era Lula" e sua estratégia econômica, não faltando diagnósticos categóricos e previsões pessimistas.

Considerando o governo Dilma Rousseff uma continuação dos dois mandatos anteriores - o que aqui se julga correto e útil -, as apreciações apontam desde uma "insustentabilidade do crescimento baseado no consumo" até a vinculação exclusiva dos bons resultados passados ao cenário internacional favorável. Chamam a atenção as críticas a um excesso de intervencionismo estatal e ao "populismo", que trocaria alguma melhora nas condições atuais de vida da população pelo comprometimento futuro das condições de crescimento e desenvolvimento. O governo Dilma, em suma, estaria recebendo "a conta" da irresponsabilidade dos dois mandatos iniciais da Era Lula, e ao insistir nas opções equivocadas estaria colhendo sucessivos fracassos ${ }^{2}$.

2 Esta visão, com variados graus de sofisticação e público-alvo, está presente em várias manifestações (artigos, entrevistas etc.) de economistas renomados como Edmar Bacha, Samuel Pessoa, Marcos Lisboa, entre outros, em coletâneas de trabalhos como GIAMBIAGI, F.; PORTO, C. (orgs.). Propostas para o governo 20I5-2oI8. Rio de Janeiro: Elsevier, 2013. Ou em obras como a de VILLA, M. A. Década perdida: dez anos de PT no poder. São Paulo: Record. Infelizmente não há espaço para uma discussão 
O presente texto, que não comunga desta percepção geral, procura jogar luz sobre o que se julga ser a característica distintiva da Era Lula em termos econômicos: uma maior sintonia entre objetivos econômicos e sociais, ou a associação entre crescimento (e outros aspectos puramente econômicos do desenvolvimento) e a busca de maior justiça social. Tal busca, adiante-se desde já, é vista aqui como limitada e insuficiente. Do mesmo modo, não é difícil identificar uma série de inconsistências e problemas na condução da economia, com diferentes graus de consequências negativas. Porém, esta que se entende como a questão econômica principal da Era Lula é tomada aqui como o eixo incontornável para a reflexão sobre a experiência recente e para o debate sobre caminhos futuros.

A hipótese com a qual se trabalha é a de que o conteúdo social do desenvolvimento brasileiro que se ensaiou na Era Lula é não apenas defensável do ponto de vista moral, como também se mostra a melhor alternativa econômica diante das dificuldades e limitações enfrentadas pelo Brasil atualmente. Indo além, defende-se que os avanços sociais experimentados, para seguirem sendo instrumento de avanço civilizatório e motor do dinamismo econômico, carecem de renovação e aprofundamento, com foco nos direitos e serviços sociais e na progressividade da carga tributária.

Com este norte, o texto está organizado em mais quatro seções além desta Introdução. Na primeira, retoma-se de maneira muito sucinta a evolução das relações entre o dinamismo econômico, o mercado doméstico e a situação social ao longo da história do Brasil. $\mathrm{Na}$ segunda, são discutidos os mecanismos e os bons resultados obtidos durante os dois mandatos de Lula (2003-2010). Na terceira, as dificuldades e os desafios explicitados durante o mandato de Dilma (desde 2011) são apresentados, bem como comentadas algumas das propostas de rumos alternativos em debate no Brasil. Por fim, a quarta seção sintetiza uma agenda de temas e prioridades para manter em curso, renovando-o, o "social-desenvolvimentismo" esboçado até aqui na Era Lula.

mais alongada destes pontos de vista, que se pode considerar dominantes no atual debate público brasileiro. Na penúltima seção, alguns argumentos e propostas são resumidos e criticados. 


\section{Breve volta a uma velha questão}

O Brasil, como é sabido, surge enquanto nação independente em 1822 carregando a herança de mais de três séculos de colonização. Entre os mais importantes legados deste período, a escravidão, a orientação primário-exportadora da economia (com sucessivas "ondas" das exportações de commodities: açúcar, borracha, ouro e café) e a consequente concentração da propriedade da terra e da riqueza. Mesmo após a independência, por mais de um século, a organização geral da economia brasileira conservou a mesma mecânica de funcionamento: uma ou duas commodities primárias como a principal fonte de receitas estrangeiras, vulnerabilidade externa (frente às oscilações periódicas nos seus preços e nas condições dos empréstimos internacionais) e nenhum papel significativo para o mercado interno enquanto alavanca do dinamismo econômico. Quanto à questão social, a melhor caracterização é a contida na citação atribuída a Washington Luís, o último dos presidentes da República Velha: era uma "questão de polícia".

Com o crash da Bolsa de Nova Iorque, em 1929, e a subsequente Grande Depressão, a economia brasileira foi severamente impactada, principalmente pela queda dos preços internacionais do café e pelo colapso do crédito comercial. Graças a medidas de autoproteção (que foram capazes de evitar a falência completa dos cafeicultores) e um incipiente processo de diversificação industrial, durante a década de 1930, o Brasil experimentou aquilo que Celso Furtado havia chamado de "deslocamento do eixo dinâmico" da economia - ou seja, as atividades domésticas foram gradualmente assumindo o papel central na atividade econômica. Durante a Era Vargas (1930-1954), cuja origem está ligada à inadequação e aos vícios do regime anterior, este processo foi intensificado, definindo o início do período "nacional-desenvolvimentista" na história brasileira - que perduraria, com importantes reconfigurações, até a década de 1980.

Juntamente com o lançamento da indústria de base no país e a criação de toda a institucionalidade do Estado brasileiro, a Era Vargas também foi marcada pela criação de algumas medidas de proteção social, notadamente, a consolidação da legislação trabalhista e a criação do salário mínimo. Longe de representar uma estratégia de desenvolvimento inclusivo (até mesmo porque os incipientes direitos sociais eram prerrogativas apenas dos trabalhadores urbanos e nada foi tentado em termos de reforma agrária), tais iniciativas foram de grande importância para o aprofundamento do mercado interno e para o aumento do multiplicador da economia. Após o esforço de industrialização, concentrado 
no governo de Kubitschek (1956-1961) e seu Plano de Metas - pelo qual a integração do território, o setor de energia e a indústria de bens de consumo duráveis deram um "salto à frente" sem grandes alterações no campo social -, o início da década de 1960 foi marcado por uma disputa decisiva entre diferentes projetos sociais e econômicos na sociedade brasileira.

O aprofundamento dos direitos sociais, defendidos sob a bandeira das "reformas de base" pelos movimentos sociais e pelo governo Goulart, acabou derrotado pelo Golpe de 1964, e no que se refere aos temas tratados no presente artigo este é seu principal significado: durante a ditadura, que durou as duas décadas seguintes, teve lugar um aprofundamento da estratégia de diversificação estrutural por meio do planejamento e intervenção estatais, tipicamente "desenvolvimentistas"; em termos sociais, o período foi de regressão e conservadorismo. Como ilustrado na Figura 1, uma relação direta entre crescimento e concentração é o grande "fato estilizado" da economia brasileira durante os anos 1960 e 1970.

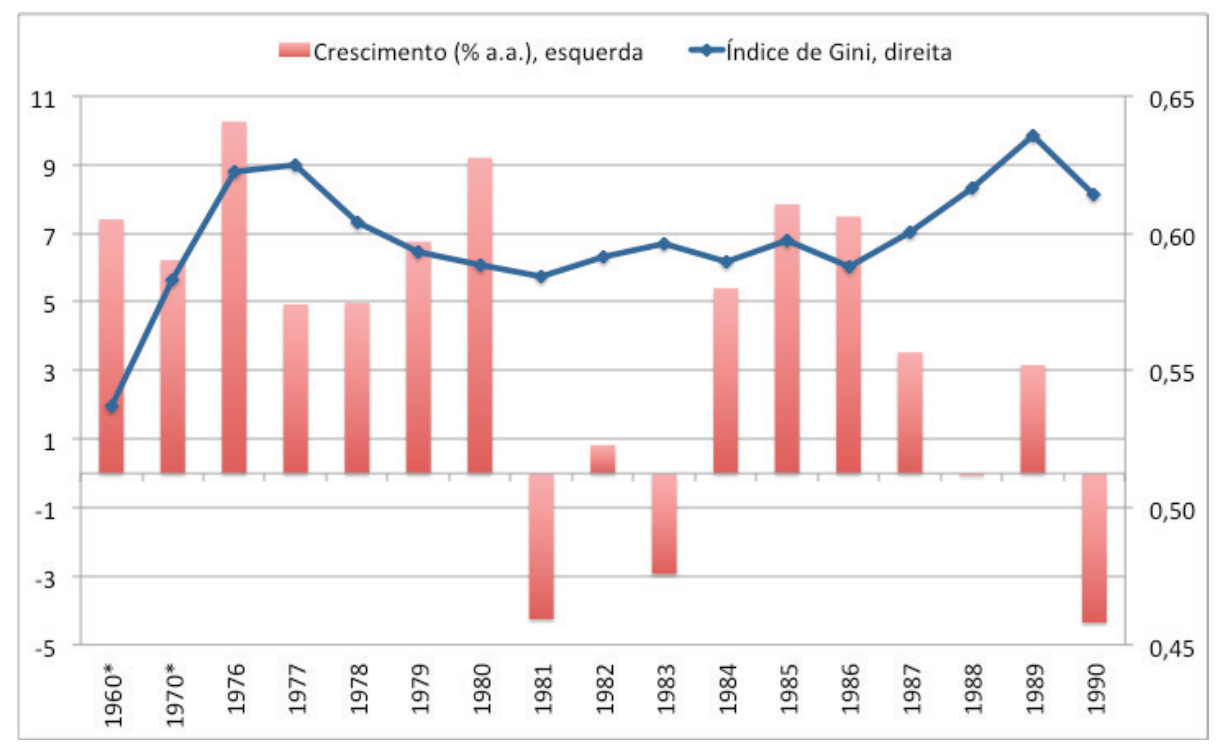

Figura 1: Crescimento econômico e distribuição de renda no Brasil (1960-1990). Fonte: Elaboração própria, a partir de dados do Ipeadata, IBGE e Neriª .

*As taxas de crescimento são médias dos 10 anos anteriores.

3 NERI, M. (org.). De volta ao país dofuturo: projeções, crise europeia e a nova classe média. Rio de Janeiro: FGV/CPS, 2012. 
Esta relação foi objeto de intensos debates acadêmicos entre intelectuais na época, com destaque para a controvérsia entre os dois maiores economistas heterodoxos brasileiros: Celso Furtado e Maria da Conceição Tavares. Ao incorporarem a questão da distribuição na análise sobre o estilo de desenvolvimento (e as possiblidades de crescimento), tais autores jogam luz sobre a questão econômica, que aqui se quer privilegiar, na Era Lula.

Para Furtado ${ }^{4}$, a industrialização brasileira era, em si, um processo intimamente relacionado à histórica concentração de renda: movida pela modernização dos padrões de consumo da parcela mais abastada da população e incorporando progresso técnico gerado no exterior, ao mesmo tempo era produto e perpetuava a desigualdade. Mais importante, a estreiteza do mercado consumidor (e bens de capital) e a redução progressiva na relação produto-capital (decorrente desta concentração de investimento investimentos no setor duráveis), levariam à tendência de estagnação da economia brasileira - o que era plausível no início dos anos 1960. Tavares e Serra ${ }^{5}$, com o benefício do tempo transcorrido (e da aceleração do crescimento ao invés da estagnação prevista), desenvolvem explicação contrária: a concentração de renda não só não era um obstáculo ao crescimento, mas poderia ser usada para promovê-lo. Segundo eles, havia sido a falta de financiamento para o investimento e a falta de demanda para torná-lo rentável a causa da perda de fôlego do crescimento após o Plano de Metas. A alteração regressiva na distribuição da renda, privilegiando as camadas médias e altas da renda - aumentando assim a demanda por bens duráveis - e uma compressão dos salários de trabalhadores de baixa qualificação - elevando os lucros acabou sendo o caminho aberto a partir das reformas e políticas do Programa de Ação Econômica do Governo (1964-1966) para enfrentar o problema da estagnação. De fato, e sem deixar de reconhecer os méritos e o pioneirismo na análise de Furtado, o Brasil conseguiu conciliar alto crescimento (especialmente durante o "milagre" de 1968 a 1973) com concentração de renda.

O "milagre", como costuma acontecer, não durou para sempre. O que era uma economia muito dinâmica, embora desigual (ou

4 FURTADO, C. Desarrollo y estancamiento en América Latina: un enfoque estructuralista. In: A. Bianchi (org.). América Latina: Ensayos de Interpretación Económica. Santiago: Ed. Universitária, 1966.

5 TAVARES, M. C.; SERRA, J. Más allá del estancamiento: una discusión sobre el estilo de desarollo reciente de Brasil. Revista Latino-Americana de Ciencias Sociales, Manizales, n. 1-2, p. 2-38, 1971. 
dinâmica porque desigual, como explicado por Tavares e seus seguidores), transformou-se em estagnação e instabilidade na década de 1980, com prejuízos sociais adicionais. A última grande tentativa organizada do regime militar de planejar o desenvolvimento brasileiro e vencer a distância que separa o país das grandes potências - o II PND, lançado em 1974, em meio a um ambiente internacional já em deterioração - foi capaz de promover mudanças importantes na estrutura produtiva, ainda que com ritmo e alcance muito aquém do planejado diante das dificuldades externas. No que se refere às desigualdades sociais e às políticas para atacá-las, não se avançou além dos diagnósticos e propostas.

O fardo da dívida externa excessiva, crescente desde o início dos anos 1970 e em muito ampliada com os projetos do II PND, e a falta de mecanismos internos para financiá-los, combinado com a escassez de financiamento externo após o aumento nas taxas de juros dos EUA em 1979, impôs muitas dificuldades e uma organização perversa para a economia brasileira durante a chamada "década perdida". 6

Era o fim do "nacional-desenvolvimentismo", sem qualquer substituto consistente. De particular importância, foi a crise fiscal e financeira do estado, uma consequência da "nacionalização" da dívida externa, que impediu qualquer possibilidade de políticas ativas, orientada para objetivos sociais. Taxas de crescimento baixas e voláteis, inflação alta e aceleracionista (com efeitos piores sobre os mais pobres, incapazes de preservar a sua renda e riqueza), e um estado geral de instabilidade macroeconômica foram as principais consequências da restrição externa e da necessidade de produzir vastos superavit comerciais para servir à dívida externa. Nessa década "perdida", a obrigatoriedade do ajuste externo era assim incompatível com o crescimento baseado no mercado doméstico e com a distribuição de renda ${ }^{7}$.

A crise final do "nacional-desenvolvimentismo", em termos econômicos, também teve grande relevância política, já que foi decisiva para a erosão do apoio ao governo militar. Mesmo sem eleições

6 Sobre o II PND, ver o posicionamento crítico de LESSA, C. Visão Crítica do II PND. Revista Tibiriçá, São Paulo, n.6, jan./mar. 1977; e o capítulo I de CARNEIRO, R. de M. Desenvolvimento em crise: a economia brasileira no ultimo quarto do século XX. São Paulo: Editora Unesp, 2002. Para o endividamento externo e suas motivações, a referência é CRUZ, P. D. Dívida externa e política econômica: a experiência brasileira dos anos setenta. São Paulo: Brasiliense, 1984 .

7 Capítulo 4 de CARNEIRO, R. de M. op. cit.; BATISTA JR., P. N. Formação de capital e transferência de recursos ao exterior. Revista de Economia Política, São Paulo, v. 7, n. 1, p. 10-27, jan./mar. 1987 . 
diretas (retomadas apenas em 1989), a nova Constituição, promulgada em 1988 foi um símbolo importante da redemocratização. Em seus capítulos sociais, criaram-se importantes mecanismos de proteção social, principalmente no que tange à Previdência Social (estendida aos trabalhadores rurais, mesmo sem contribuições anteriores), à saúde pública (tornada universal e gratuita, com a criação do SUS) e aos direitos trabalhistas (férias remuneradas, seguro-desemprego, direito de greve etc.). Mesmo considerando os graves problemas de financiamento (que se explicitariam nos anos posteriores), as conquistas constitucionais foram as sementes do que mais próximo se chegou de um "Estado de Bem Estar Social" no Brasil - justificando não apenas o apelido de "Constituição Cidadã" para a Carta de 1988, mas também a feroz oposição a ela em círculos liberais.

Graças à renegociação das dívidas externas sob o "Plano Brady" (no caso brasileiro, concluído apenas em 1994), às mudanças nas relações financeiras internacionais que caracterizam a globalização financeira e às taxas de juros baixas nas economias centrais no início da década de 1990, uma nova fase de abundância de financiamento externo se apresenta para a América Latina naquele momento, encerrando a "década perdida" e abrindo caminho para uma nova estratégia de desenvolvimento. Consolidada sob o chamado "Consenso de Washington", a agenda das reformas liberalizantes era, nesta parte do mundo, uma resposta à crise do modelo anterior e esteve centrada na redução do papel do estado no processo de desenvolvimento.

No Brasil, tal agenda - lançada pelo abreviado governo Collor foi consolidada no período FHC (1995-2002), e em muito facilitada pelo apoio político conquistado com o sucesso no combate à alta inflação por meio do Plano Real. A diminuição do índice de preços oficial (que, após um pico de quase $2500 \%$ em 1993, caiu para $22,4 \%$ em 1995, 9,6\% em 1996 e 5,2\% em 1997) resulta imediatamente em uma sensível melhoria no rendimento real dos mais pobres.

Na realidade, os ganhos distributivos da tentativa anterior (e rapidamente fracassada) para controlar a inflação, o Plano Collor (1990), foram maiores (ver Figura 1). Isso se deu principalmente porque o plano foi capaz de interromper uma série de mecanismos, desenvolvidos durante a década de 1980, para proteger a renda real da inflação acelerada. Essas ferramentas de defesa eram distribuídas de forma desigual (dependendo do acesso a contas bancárias e do próprio patamar de rendimentos), de modo que não só a inflação em si era perversa, mas também seus efeitos sociais. Esta dinâmica foi responsável pela elevação na concentração de renda durante a 
segunda metade da década de 1980, e pela a estabilidade (com uma ligeira diminuição) do Índice de Gini em torno de 0,6 a partir de 1995, apenas recuperando a situação extremamente injusta de uma década antes (Figura 2). Seja como for, após a estabilização, em 1994, durante algum tempo a expansão do mercado interno (também alimentado pela expansão do crédito) parecia assumir o papel principal.

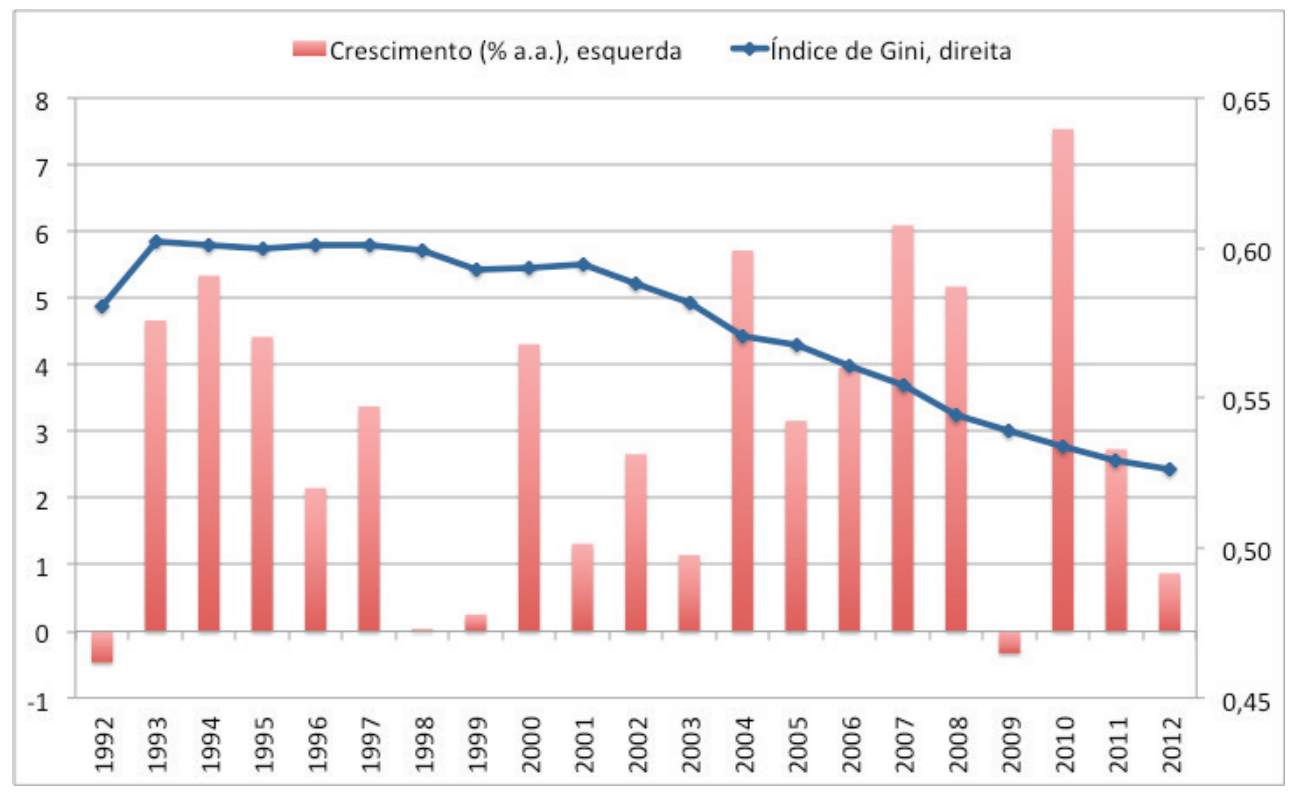

Figura 2: Crescimento econômico e distribuição de renda no Brasil (1990-2000). Fonte: Elaboração própria, a partir de dados do Ipeadata e IBGE.

Entretanto, a dinâmica da economia "modernizada" não foi particularmente favorável ao crescimento durante os anos que se seguiram, nem esteve particularmente orientada para o mercado interno ou para o desenvolvimento social. Devido à abertura comercial e financeira às privatizações e a própria atração de investimentos estrangeiros diretos, o nível de concorrência internacional foi elevado no espaço econômico doméstico. Com a contribuição da forte apreciação da taxa de câmbio, esse processo foi longe demais e tornou-se improdutivo em termos de ganhos de eficiência, resultando em falências, desemprego e desnacionalização. A regressão da estrutura produtiva também foi acompanhada pela deterioração das finanças públicas (prejudicada pela estratégia macroeconômica de valorização cambial e acumulação de reservas internacionais) e 
pela inadequação de um sistema tributário complexo e regressivo, que assistiu a um forte aumento da carga tributária total. Para piorar, a economia esteve durante todo o período sujeita à volatilidade dos fluxos internacionais de capital e testemunhou três episódios de crise cambial - 1998-1999, 2001 e 2002 - que foram enfrentadas seguindo o receituário ortodoxo tradicional: assistência de liquidez do FMI, cortes de gastos públicos e elevação nas taxas de juros.

$\mathrm{O}$ ambiente resultante de todos estes processos era estável em termos de inflação (para os padrões brasileiros), mas muito instáveis em um sentido macroeconômico mais amplo: crescimento baixo e volátil (a média anual foi de apenas 2,3\% entre 1995 e 2002), altas taxas de juros (com picos de quase 50\%, mesmo após o controle da inflação o nível nominal da taxa de política nunca caiu a menos de $15 \%$ ao ano), taxa de câmbio oscilante e, particularmente prejudicial do ponto de vista social, alto desemprego (que aumentou continuamente durante a década de 1990 e atingiu $20 \%$ da força de trabalho em 2002 e 2003). Neste contexto, o ritmo muito modesto da queda no Índice de Gini, após os ganhos iniciais com a estabilização de preços (Figura 2), não surpreende.

Em suma, esta breve retrospectiva sugere que, ao longo da história brasileira, a relação entre as dimensões sociais e econômicas de desenvolvimento nunca foi o elemento central da estratégia de crescimento. Partindo da herança colonial, passando pelo desenvolvimentismo com forte presença estatal e chegando à agenda liberal dos anos 1990, o atendimento das necessidades (mesmo as mais básicas) da maioria da população sempre foi um objetivo secundário. Obviamente, nessa trajetória, há alguns momentos muito importantes em termos de avanços institucionais (os direitos trabalhistas e o salário mínimo durante a Era Vargas; o capítulo social da Constituição de 1988) e ganhos concretos (especialmente a redução da desigualdade na sequência da queda da taxa de inflação entre 1990 e 1994). Mas inegável é o fato de que o Brasil iniciou o século XXI como uma das sociedades mais desiguais do mundo, apesar dos avanços democráticos e econômicos nas décadas anteriores.

É neste campo que vai se localizar a principal questão econômica (e social) da Era Lula. 


\section{Mudanças e otimismo: distribuição de renda e retomada do crescimento no governo Lula (2003-2010)}

Em termos teóricos, a proposição de uma associação virtuosa entre crescimento econômico e progresso social não é novidade mesmo levando-se em conta a natureza intrinsecamente excludente do capitalismo. As experiências social-democratas da Europa Ocidental durante a "Era de Ouro" de Bretton Woods são o melhor exemplo histórico de uma estratégia em que a melhoria das condições de vida (emprego, salários, direitos sociais, sistemas previdenciários e serviços públicos) não se opõe à acumulação privada de capital e ao crescimento econômico. Pelo contrário, ambas as dimensões se autorreforçavam naquele arranjo extraordinário em termos históricos.

Nada de semelhante ocorreu no Brasil nos anos 1950 e 1960: nem o contexto histórico da Guerra Fria e a ameaça comunista, nem a construção de qualquer coisa próxima a um Estado de Bem Estar Social. Como já comentado, uma versão mais fraca de um sistema de proteção social no Brasil foi produto dos esforços de redemocratização somente no final dos anos 1980, e mesmo assim enfrentou (na verdade ainda enfrenta) uma série de dificuldades operacionais e de financiamento, quando colocado em prática. Mas certamente as lições do mundo avançado iluminavam as propostas dos legisladores e policymakers brasileiros no período, e também serviam de inspiração para alguns intelectuais e políticos progressistas. Entre essas ideias, se encontra uma simples lição macroeconômica, relacionada com as fontes e o tamanho da demanda agregada: o aumento do mercado - em uma sociedade na qual grande parte da população que tinha sido, historicamente, excluída do consumo de uma vasta gama de produtos, poderia ser um poderoso motor econômico.

Mesmo que tal exclusão não tenha sido determinante para uma tendência de estagnação durante as décadas de 1960 e 1970, sua superação não deixou de ser vista como uma grande fonte potencial de crescimento, pelo menos por alguns economistas heterodoxos. De acordo com Bielschowsky ${ }^{8}$, a ideia de um mercado de consumo de massa, a ser explorada por uma estrutura de oferta específica, foi tratada academicamente pela primeira vez por Castro ${ }^{9}$, mas era

8 BIELSCHOWSKY, R. Estratégia de desenvolvimento e as três frentes de expansão no Brasil: um desenho conceitual. Economia e Sociedade, Campinas, v. 21, n. especial, p. 729-747, 2012. DOI: http://dx.doi.org/10.1590/So104-06182012000400002

9 CASTRO, A. B. O Brasil a caminho do mercado de consumo de massa. In: REIS VELLOSO, J. P. (coord.). As perspectivas do Brasil e o Novo Governo. São Paulo: Nobel, 1990. 
parte importante do ideário econômico do Partido dos Trabalhadores desde a sua fundação em 1980.

A eleição de Lula em 2002, no contexto econômico difícil, descrito no final da seção anterior, foi embalada por um discurso econômico em que tal proposição já era "moderada" por sinalizações ao mercado e promessas de ortodoxia. Durante os primeiros anos do governo, estes últimos aspectos prevaleceram.

A política econômica foi claramente orientada para o controle da inflação e a redução da dívida pública, por meio de uma política monetária muito restritiva, grandes superavit fiscais, apreciação da taxa de câmbio e uma agenda de reformas estruturais em linha com as diretrizes predominantes no governo anterior. Certamente, a urgência das condições objetivas - a inflação acumulada chegou a quase $10 \%$ no início de 2003 , a dívida pública líquida ultrapassou $60 \%$ do PIB no final de 2002 e a taxa de câmbio chegou a se aproximar de R \$,00 por dólar - foi importante para esta opção inicial, o que não diminui o seu caráter conservador nem seus efeitos negativos. A baixa taxa de crescimento em 2003 acabou sendo compensada por um controle gradual das outras variáveis macroeconômicas importantes. Além disso, a melhoria da situação econômica mundial nos anos seguintes (particularmente as baixas taxas de juros nas economias centrais, a retomada dos fluxos de capital para países em desenvolvimento e a fase ascendente de preços de commodities primárias) também desempenhou papel crucial na recuperação da economia brasileira.

O crescimento do PIB em 2004 (5,7\%, depois de apenas 1,1\% no ano anterior) iniciou uma sequência de cinco anos positivos. Neste período, o dinamismo da economia, ainda que longe dos patamares observados nos anos 1960 e 1970, teve a maior média em mais de duas décadas, atingindo 4,8\%. Considerando-se todo o governo Lula, já incluídos o ano de crise de 2009 (queda de 0,3\% do PIB) e a recuperação em 2010 (7,5\%), essa média fica em torno de 4,1\%.

A característica mais importante desta recuperação, no entanto, não foram os valores, mas, sim, seus motores e consequências. Se a forte demanda externa puxou a economia em 2002 e 2003, a contribuição da demanda doméstica para o crescimento do PIB tornou-se predominante de 2004 em diante. Considerados os baixos níveis de investimento que ainda persistem (no auge dos últimos anos, chegou a apenas 19,5\% do PIB em 2010), o principal componente deste dinamismo é o consumo. É aqui que reside a grande novidade na história brasileira: a ampliação consistente do mercado 
de consumo como estimulador da atividade econômica - uma relação que, como comentado acima, já frequentava as formulações teóricas de economistas progressistas algum tempo antes, e que neste período se tornou realidade de maneira diametralmente oposta à verificada nos anos de 1960 e 1970, quando a concentração era funcional para promover o crescimento.

O Î́ndice de Gini, em suave redução ao longo dos anos 1990, acelera seu ritmo de queda: de 0,588 em 2002, chega a 0,539 mesmo no difícil ano de 2009 (Figura 2). Mais do que isso, a parcela de famílias que vivem abaixo da linha de pobreza (estabelecida em $\mathrm{R} \$ 705,00$ mensal, a preços de 2009) diminuiu de 28,1\% em 2003 para 15,3\% em 2009. Considerando a extrema pobreza (o valor para uma família consumir o mínimo de calorias necessárias para o seu membro), a queda é igualmente impressionante: 11,3\% em 2003 e 5,8\% em 2009. Ainda de acordo com dados oficiais, o crescimento da renda dos pobres entre 2001 e 2009 foi significativamente maior do que o dos ricos: os primeiros $10 \%$ do espectro de distribuição experimentaram, em média, um aumento de $7,2 \%$ ao ano, enquanto que para os $10 \%$ mais ricos esta taxa foi de $1,4 \%{ }^{10}$. Em termos de capacidade de consumo, esta transformação significa a ascensão de 25 milhões de pessoas da classe "D" para "C"- que no final do governo Lula representava 50\% da população, ou cerca de 100 milhões de brasileiros ${ }^{11}$.

Essas transformações não são resultantes de um único fator ou política. É justo considerar que o inicial conservadorismo econômico do governo Lula foi sendo gradualmente substituído, especialmente em uma dimensão estrutural, por uma concepção diferente sobre o papel do Estado, o tamanho e a importância dos bancos públicos e outras empresas estatais, por mecanismos de planejamento central, revalorização do investimento público etc. Mesmo mantendo-se muito ortodoxa na gestão macroeconômica, a condução geral da economia foi transitando em direção a uma nova versão do "desenvolvimentismo", no qual os novos elementos foram o foco na estabilidade macroeconômica e, especialmente, a crescente importância dada aos aspectos sociais do desenvolvimento (ou,

10 Todos estes e os próximos números citados ao longo do texto, quando não explicitamente mencionado, têm como fonte o IBGE.

11 Esta foi a base para o slogan oficial considerando o Brasil um "país de classe media". Para as ideias a respeito da emergência de uma "nova classe média", ver, por exemplo, NERI, M. op. cit. Em termos sociológicos, estatísticos e mesmo econômicos, não parece se tratar de um conceito muito rigoroso - mas certamente este não é o espaço adequado para tal discussão. 
especificamente, à ampliação do mercado consumidor) ${ }^{12}$. Devido a esta última característica, alguns autores têm denominado a estratégia de "social-desenvolvimentista". ${ }^{13}$

Para além destas tendências gerais, do cenário internacional favorável e das boas condições macroeconômicas, foram quatro os principais determinantes específicos da "criação" de um mercado de consumo de massas no Brasil - nem todos devidamente reconhecidos no debate público brasileiro: políticas de transferência de renda; o sistema de proteção social; a política de valorização do salário mínimo; algumas transformações; e o bom comportamento do mercado de trabalho durante o período. Interagindo com esses processos, mas também respondendo a outras fatores, a expansão do crédito interno também desempenhou papel importante.

O primeiro instrumento foram as políticas de transferência de renda voltadas para as camadas mais pobres da população. $\mathrm{O}$ carro chefe foi o programa Bolsa Família - um pagamento mensal a famílias cuja renda não atinge patamares mínimos pré-determinados e que se comprometem com algumas contrapartidas relacionadas ao futuro das crianças (frequência à escola, campanhas de vacinação etc.). A ideia de um "imposto de renda negativo" não foi uma criação da equipe de Lula: versões anteriores já haviam sido implementadas anteriormente em algumas cidades do Brasil e mesmo na esfera federal. Mas o tamanho e o impacto do programa, seu alcance e toda a tecnologia envolvida são claramente uma das marcas distintivas deste governo. É sem dúvida a experiência mais avançada de política social focada no mundo, não apenas por sua extensão, mas também pela eficiência.

12 Para uma visão geral desta transição durante o governo Lula, com atenção especial ao papel do Estado, ver LOPREATO, F. L. Caminhos da Política Fiscal do Brasil. São Paulo: Editora Unesp, 2013. Para um balanço da política econômica sob Lula, ver BARBOSA FILHO, N.; SOUZA J. A. P. A inflexão do governo Lula: política econômica, crescimento e distribuição de renda. In: SADER, E; GARCIA, M. A. (orgs.) Brasil: entre o Passado e o Futuro. São Paulo: Editora Fundação Perseu Abramo/Boitempo, 2010.

13 CARNEIRO, R. de M. Novos e velhos desenvolvimentismos. Economia e Sociedade, Campinas, v. 21, n. especial, p. 749-778, 2012. DOI: http://dx.doi.org/10.159o/So104o6182012000400003; BASTOS, P. P. Z. A economia política do novo-desenvolvimentismo e do social-desenvolvimentismo. Economia e Sociedade, Campinas, v. 21, n. especial, p. 779-810, 2012. DOI: http: //dx.doi.org/10.1590/So104-06182012000400004; COSTA, F. N. Desenvolvimento do desenvolvimentismo: do socialismo utópico ao social-desenvolvimentismo. Texto para Discussão IE-Unicamp, n. 205, maio 2012. Disponível em: <http://www.eco.unicamp.br/docprod/downarq.php?id=3185\&tp =a>. Acesso em: out. 2013 . 
A partir de 2004 (quando outras iniciativas na mesma direção foram unificadas no Bolsa Família) até 2011, o número de beneficiados mais do que duplicou (atingindo 13,4 milhões de famílias). Durante este período, a despesa total aumentou de $0,20 \%$ para $0,41 \%$ do PIB (cerca de R 17 bilhões), cifras modestas quando comparadas a quase $6 \%$ do PIB utilizados no pagamento de juros da dívida pública nesse mesmo ano. Há valores diferentes para o benefício, dependendo da renda originária da família, mas todos se situam abaixo do salário mínimo.

Mas o Bolsa Família não é a única política de transferência de renda a se destacar. O Benefício de Prestação Continuada (BPC), consolidado pela Constituição de 1988, é uma espécie de pensão paga aos trabalhadores rurais que não contribuíram durante sua vida ativa. Em 2011, 3,9 milhões de pessoas receberam esse benefício, mas o valor total pago é muito maior que o custo do Bolsa Família em mais de $\mathrm{R} \$ 30$ bilhões. A razão para a diferença é sua indexação ao salário mínimo. O BPC é, de fato, uma das faces mais visíveis do amplo sistema de proteção social brasileiro, o segundo grupo de determinantes dos avanços sociais recentes. De acordo com Castro ${ }^{14}$, o total dos gastos sociais do sistema de previdência alcançavam 11,8\% do PIB em 2010, divididos em 7,4\% direcionados a trabalhadores aposentados do setor privado ( 28 milhões de benefícios, dos quais 19 milhões são equivalentes ao salário mínimo) e 4,4\% para os beneficiários do setor público (4,3 milhões de pessoas, todas acima do mínimo).

Como fica claro por estes números, a própria política de salário mínimo é, em si, um poderoso instrumento para o desenvolvimento social no Brasil. Se somados aos anteriores os quase 9 milhões de trabalhadores do setor privado, cujos pagamentos são iguais a este piso, seu impacto direto é de mais de 30 milhões de pessoas. Indiretamente, o salário mínimo é também um parâmetro importante para as negociações salariais privadas. Criado na década de 1930, este instrumento de regulação sofreu um processo de erosão do seu valor real ao longo do tempo, especialmente durante o período do regime militar (em que foi uma das ferramentas para a concentração de renda). Desde 1990, em termos reais, a tendência foi de estagnação ou de aumentos tímidos, que claramente se aceleram

14 Castro, J. A. Política social e desenvolvimento no Brasil. Economia e Sociedade, Campinas, v. 21, n. especial, 2012, p. 1011-1042. DOI: http://dx.doi.org/10.1590/So104o6182012000400012 
durante o governo Lula. O ganho real, entre 2003 e 2010, foi de 56\%, quase o dobro do aumento verificado nos oito anos anteriores. Mais importante ainda, desde 2006 vigora uma regra estável para a definição deste preço (válida até 2015, quando deve ser rediscutida pelo Congresso): o aumento em cada ano deve ser igual à taxa de inflação do anterior, somando-se o crescimento do PIB verificado dois anos antes - em uma tentativa de transferir os ganhos de produtividade para os salários-base da economia.

Conectado aos outros três, o quarto determinante consiste no comportamento favorável do mercado de trabalho ao longo da última década. Ele foi marcado, em primeiro lugar, por um intenso processo de formalização: a criação de empregos formais nos oito anos, encerrados em 2010, foi de mais de 15 milhões, a participação dos empregadores com carteira assinada subiu de $45 \%$ para $52 \%$ da força de trabalho, e os contribuintes para o sistema de seguridade social representavam, em 2011, $72 \%$ da população ocupada (em 2002, essa relação era de 63\%). As taxas de desemprego, uma das características negativas da macroeconomia brasileira durante a década de 1990, inverteu a tendência e caiu ano após ano: de uma média anual de quase $12 \%$ da força de trabalho em 2002, para 6,6 \% em 2010.

Por fim, outro ingrediente fundamental na receita de crescimento e expansão do mercado doméstico foi o crescimento das operações de crédito. Estimulados por algumas medidas regulatórias (com destaque para garantias relacionadas ao crédito habitacional), uma importante inovação financeira (o crédito consignado) e, especialmente, as melhorias no mercado de trabalho e na renda, os bancos expandiram o a concessão de crédito para pessoas físicas e empresas. A relação entre crédito total e PIB, que havia iniciado 2003 em apenas $25 \%$, terminou 2010 acima de $45 \%$ (um valor ainda baixo para padrões internacionais).

Movida por todos esses processos, a economia brasileira registrou, em 2010, uma taxa de crescimento anual de 7,5\%, em forte recuperação depois dos impactos da crise internacional em 2009. O otimismo justificado seria uma ferramenta importante na campanha eleitoral daquele ano. 


\section{Exaustão e frustrações? Desaceleração e desafios ao governo Dilma (2011-2013)}

Dilma Rousseff foi escolhida para ser a candidata oficial à sucessão de Lula com base em seu trabalho como Chefe da Casa Civil desde 2005, apesar de sua completa inexperiência em disputas eleitorais. Apoiada por uma ampla coalizão política e depois de uma campanha eleitoral difícil (na qual nenhum dos candidatos da oposição atacou diretamente as bandeiras sociais de Lula), ela assume o cargo no início de 2011 com expectativa de continuidade da estratégia geral e melhorias na capacidade de gestão.

Após o crescimento exuberante durante o ano eleitoral, alguma desaceleração era prevista pelo governo em 2011 - na verdade, era até desejada, dada a aceleração da inflação e o ritmo muito forte de expansão do crédito. Os primeiros movimentos macroeconômicos do novo governo foram nessa direção: cortes de gastos (que no Brasil sempre afetam o investimento público mais do que os gastos correntes) e aumento das taxas básicas de juros e "medidas macro prudenciais" para controlar o crédito. Algum tempo depois, é possível dizer que não apenas o leque de instrumentos e a dose foram exagerados, mas que também houve uma leitura errada do contexto internacional (em que a crise se desdobraria em novas pressões deflacionárias) e uma prudência excessiva com a inflação (que não se movia principalmente por excesso de demanda). Algumas outras causas específicas escândalos de corrupção que impediram a evolução dos projetos de infraestrutura, dificuldades burocráticas etc.- também podem ser consideradas, mas o fato é que a desaceleração foi fortemente influenciada pela mudança de direção na política econômica no início do mandato, especialmente na frente fisca ${ }^{15}$. Os efeitos contracionistas foram acentuados e perduraram: o PIB cresceu 2,7\% em 2011, apenas 0,9\% em 2012 e 2,3\% em 2013.

No primeiro trimestre de 2012, o excesso de conservadorismo ficou claro até para os condutores das políticas, e o mix macroeconômico começou a mudar. Uma redução importante nas taxas de juros básicas (até o piso histórico de 7,25\% ao ano em termos nominais) e um maior controle sobre a taxa de câmbio (neutralizando, em parte, as pressões pela apreciação) foram movimentos importantes, mas no front fiscal novos problemas surgiram. Incapaz ou pouco disposto a

15 SERRANO, F.; SUMMA, R. A desaceleração rudimentar da economia brasileira desde 2011. Oikos, Rio de Janeiro, v. 11, n.2, p. 166-202. 2011. 
retomar a curva ascendente do investimento público, o governo optou pela promoção do investimento privado por meio de uma série de isenções fiscais descoordenadas para setores produtivos específicos. A falta de contrapartidas (em termos de investimentos, exportações etc.) parece importante para entender por que, apesar de prejudicarem as receitas públicas, tais medidas não foram suficientes para reacelerar a economia e a produção industrial como um todo (apesar de contribuírem para sustentar o emprego). Aparentemente, o efeito foi mais positivo sobre a rentabilidade das empresas beneficiadas do que sobre suas decisões de produzir e investir no país.

Na dimensão social, os resultados do período Dilma permanecem positivos. Com um aprimoramento da estratégia focalizada no combate à pobreza extrema - o programa Brasil Sem Miséria e a continuidade dos aumentos do salário mínimo (que atualmente somam alta de $75 \%$ em termos reais, desde 2003), a distribuição de renda pessoal continuou melhorando e, em 2012, o Índice de Gini reduziu-se para menos de 0,50 - patamar em que se encontrava no início da década de 1960. Também muito importante, o mercado de trabalho vem mostrando surpreendente resiliência: mesmo com o crescimento em declínio, as taxas de desemprego seguiram em queda e se encontram em seus mínimos históricos, com média anual de apenas 5,5\% em $2012^{16}$.

Mas, em termos das (más) notícias econômicas, o problema vai além do baixo dinamismo. A deterioração das contas externas (com o déficit em conta corrente girando em torno de 3,5\% do PIB), a taxa de inflação rondando os limites superiores da meta oficial $(6,5 \% \mathrm{em}$ 2011, 5,8\% em 2012 e 5,91\% em 2013) e a piora nas contas fiscais, em grande parte explicada pela queda na receita, também ajudaram a espalhar uma convenção pessimista sobre macroeconomia brasileira. A estrutura produtiva mostra claros sinais de regressão, com os coeficientes de importação na indústria e os déficit comerciais em manufaturados aumentando acentuadamente. Pelo lado estrutural, os problemas notórios de infraestrutura logística e energia têm sido enfrentados de forma lenta. A esperança neste campo está concentrada no amplo pacote em curso de concessões (estradas, ferrovias,

16 As causas deste comportamento são complexas e estão sujeitas a intenso debate. Mas a situação não deveria ser tomada como "pleno emprego", como fazem analistas ortodoxos (defensores de medidas recessivas). Para um panorama das transformações recentes no mercado de trabalho brasileiro, ver BALTAR, P. Crescimento da Economia e Mercado de Trabalho no Brasil. Campinas, Ipea/IE - Unicamp, 2013. (mimeo) 
aeroportos e projetos de energia, incluindo as reservas de petróleo da camada pré-sal) para o setor privado.

Teria, enfim, chegado a um limite no governo Dilma a combinação virtuosa entre produção e consumo de massas? O modelo bem-sucedido da Era Lula estaria se provando insustentável ou de fôlego curto? Diferentes e importantes atores do debate público brasileiro têm respondido afirmativamente a estas perguntas. Em grande parte dos casos, a lógica econômica por trás do raciocínio é duvidosa, especialmente a proposição de reduzir o consumo a fim de ampliar os investimentos. Mas o ponto a destacar é que as alternativas propostas, em geral, representam um risco para a associação virtuosa entre as melhorias econômicas e sociais, a característica principal da Era Lula enfatizada neste trabalho.

De um lado, assiste-se a uma nova versão da agenda liberal para o Brasil sendo formulada e propagada por alguns setores intelectuais e financeiros com grande exposição midiática ${ }^{17}$. As principais propostas em pauta são: uma nova rodada de abertura comercial (de maneira unilateral), a redução do tamanho e a reversão nos papéis assumidos pelo Estado recentemente, uma gestão macroeconômica mais ortodoxa (especialmente, um ajuste fiscal importante), a redução dos custos do trabalho e uma ênfase genérica em educação e qualificação profissional. Como seria de esperar de uma formulação liberal, nenhum papel virtuoso está reservado para a dimensão social na estratégia econômica, mas o caráter universal de alguns aspectos do sistema de proteção social brasileiro é claramente criticado, e políticas mais focadas são recomendadas.

Tal visão parece baseada em uma concepção muito primária de vantagens competitivas, às vezes defendendo explicitamente a reespecialização da economia brasileira, sem qualquer atenção às consequências em termos de emprego, salários, sustentabilidade intertemporal das contas externas etc. Mais importante para o tema de fundo aqui tratado, sem os ganhos distributivos como os causados pela redução da inflação em 1994 (quando ideias similares se tornaram hegemônicas no Brasil), uma mudança de estratégia nesta direção provavelmente significaria uma reversão no caráter social do desenvolvimento insinuado na última década.

17 Ver, entre outros exemplos, BACHA. E.; BOLLE, M. (orgs.). O futuro da indústria no Brasil: desindustrialização em debate. Rio de Janeiro: Civilização Brasileira; e GIAMBIAGI,. F.; PORTO, C. (orgs.) op. cit. 
Por outro lado, ganhou espaço no debate público e no interior do governo uma visão heterodoxa sobre questões macroeconômicas, apresentada como uma estratégia de desenvolvimento, o chamado "novo desenvolvimentismo"18. Criticando o crescimento com poupança externa e a apreciação da taxa de câmbio, e especialmente preocupados com o processo de "desindustrialização", a receita destes analistas é concentrada em medidas de política macroeconômica. Uma importante desvalorização da moeda nacional (com vistas a emular a estratégia asiática de crescimento export-led), cortes nas taxas de juros e políticas de ajuste fiscal (ou corte de gastos) são as principais propostas objetivas.

Apesar de antiliberal e voltado para a questão fundamental da regressão produtiva em curso, este conjunto de ideias também se mostra "neutro" a respeito do progresso social como motor econômico. Além disso, a ambição de um crescimento liderado pelas exportações no Brasil parece ignorar todas as outras vantagens dos países industrializados da Ásia (liderança tecnológica, as decisões estratégicas das empresas multinacionais a respeito de sua localização, barreiras à entrada etc.) e pode ser entendida como uma defesa de salários mais baixos como complemento ao menor valor da moeda nacional em busca da competitividade. Em alguns casos, a "neutralidade" sobre a relação entre os objetivos sociais e econômicos se transforma em oposição explícita: Oreiro $^{19}$, um dos principais expoentes da agenda, elenca a "moderação salarial" e a "estabilidade da distribuição funcional da renda" como ingredientes necessários de uma política macroeconômica "novo-desenvolvimentista". Os riscos sociais aqui, portanto, também estão claros.

Mas o debate, a busca por alternativas e uma insatisfação difusa não se restringem à área econômica. Graças a um estilo presidencial menos disposto a negociações políticas constantes e a alguns vícios do sistema brasileiro, o governo vem enfrentando dificuldades parlamentares - que crescem em linha com os resultados econômicos ruins. A popularidade do presidente, no entanto, sustentada

18 O principal expoente desta visão é o ex-ministro Luiz Carlos Bresser-Pereira, mas há um importante grupo de seguidores de várias universidades brasileiras. Uma compilação completa dos documentos e artigos acadêmicos sobre o novo-desenvolvimentismo e o debate sobre ele está disponível em: <http://www.bresserpereira. org.br/novodesenvolvimentismo.asp >. Acesso em out. 2013.

19 OREIRO, J. L. Novo-desenvolvimentismo, crescimento econômico e regimes de política macroeconômica. Estudos Avançados, São Paulo, v. 26, n. 75, p. 29-40, maio/ ago. 2012. DOI: http://dx.doi.org/10.1590/So103-4014,2012000200003 
em máximos históricos, parecia inabalável até meados de 2013, sustentada em patamares históricos explicados pelos resultados em termos de emprego e renda. Deste ponto de vista, o modelo parecia longe de estar esgotado.

Em junho de 2013, uma surpreendente onda de manifestações em massa mudou completamente o panorama político. Iniciado por um pequeno grupo em São Paulo protestando contra o aumento das tarifas de transporte público, o movimento se espalhou em poucos dias para todas as grandes cidades do país e o número total de participantes passou a ser contado em milhões. É difícil encarar todos os protestos como um fenômeno único, dada a grande variedade de reivindicações: da melhoria dos sistemas de educação e saúde pública ao cancelamento da Copa do Mundo de 2014, de um transporte público melhor a um desejo genérico de menor corrupção. Apesar de ameaças de desestabilização política, o movimento perdeu força em julho e nos meses seguintes (salvo alguns focos localizados com pautas específicas e grupos com táticas mais radicais), e um de seus legados principais foi uma queda brusca na popularidade presidencial. Na verdade, a opinião sobre todos os poderes estabelecidos caiu acentuadamente, mas a maior parte da insatisfação foi dirigida contra o governo central.

Ainda há muita controvérsia sobre o significado das revoltas e as suas consequências políticas são ainda incertas. Para os limitados objetivos deste texto, a pergunta chave seria: trata-se de mais um sinal de esgotamento do exitoso modelo da Era Lula, desta vez emanando da sua suposta grande virtude, os avanços sociais da última década?

Políticos de oposição, atores econômicos relevantes e a opinião publicada predominante (mesmo na imprensa internacional ${ }^{20}$ ) não têm dúvidas a respeito disso. No entanto, não parece claro se se trata mais do desejo de um grupo de interesses ou de um sentimento real da população. Se, em termos econômicos a ideia de exaustão, é baseada em uma piora objetiva dos indicadores, no campo social a realidade pode ser lida no sentido oposto: as pessoas querem mais. Não exatamente mais do mesmo, mas certamente na mesma direção: um ritmo mais rápido de inclusão e de melhorias em outros aspectos da desigualdade brasileira, não tocados pelas transformações dos últimos anos.

20 Ver a reportagem especial, alinhada com a nova versão da agenda liberal para 0 Brasil resumida algumas páginas acima, publicada em 28 de setembro de 2013 pela revista britânica The Economist, "Has Brazil blown it?". 
De acordo com alguns pronunciamentos recentes, esta é a leitura oficial das manifestações. No presente texto, é a base para a proposição de uma renovação e aprofundamento do conteúdo social do modelo de desenvolvimento brasileiro. Esta é a tarefa da última seção.

\section{Uma agenda "social-desenvolvimentista" renovada e mais profunda}

$\mathrm{Na}$ apertada síntese nesta última seção, dois conjuntos de propostas para "corrigir" o rumo do desenvolvimento no Brasil - o liberal e o "novo-desenvolvimentista"- foram considerados inadequados (apesardasclarasvantagens do segundo emrelaçãoaoprimeiro) por causa de seu tratamento insuficiente ou regressivo da questão social. A justificativa para isso é a concepção de que qualquer estratégia desconectada da missão de reduzir as enormes desigualdades sociais que marcam a sociedade brasileira não parece adequada nem muito promissora em termos práticos - no contexto atual. Em uma palavra, a dimensão social deve estar no centro da agenda ${ }^{21}$.

Tal ênfase não tem como objetivo principal explicar ou elogiar a trajetória recente, e muito menos de transmitir a ideia de que as mudanças ocorridas são suficientes ou garantidas. Pelo contrário, o caráter social é muito mais justificado pelos desafios (e, no sentido virtuoso aqui proposto, as oportunidades) à frente do que pelos avanços obtidos. E há várias razões para isso.

A primeira delas refere-se ao alto nível de concentração de renda que ainda existe no Brasil. Embora importante, a redução do Índice de Gini para cerca de 0,5 simplesmente coloca o Brasil entre os 10 ou 20 países mais desiguais do mundo. No caso da concentração de renda, assim como em outras variáveis econômicas e sociais, quando se parte de um nível muito desfavorável, as melhoras são mais fáceis no início do processo e tendem a exigir novos instrumentos, criatividade e alguns enfrentamentos para se manter em curso.

Nesta linha, a segunda razão é o fato de que os resultados positivos se concentraram principalmente em uma das dimensões da

21 Para uma exposição mais detalhada das ideias apresentadas nesta seção (incluindo considerações sobre a política macroeconômica, o papel do Estado e a estrutura produtiva), ver BIANCARELLI, A. M.. Por uma agenda social-desenvolvimentista para o Brasil. FPA Discute: Desenvolvimento. São Paulo: Fundação Perseu Abramo, p. 49-66, jul. 2013. Disponível em: <http://novo.fpabramo.org.br/sites/default/files/ fpa-discute-desenvolvimento-v2-1.pdf $>$. Acesso em: out. 2013. 
desigualdade: a concentração de renda pessoal (complementada pela redução não menos importante nos índices de miséria e pobreza). Muito mais difícil de medir, a concentração de riqueza no Brasil é provavelmente pior do que a concentração de renda, e há razões para imaginar que tenha piorado nos últimos anos. Índices de desigualdade com outras abordagens, como as condições de vida e de consumo, indicadores de acesso ao saneamento, educação e saúde, mostram melhorias muito mais tímidas nos últimos anos, quando não uma elevação nas diferenças ${ }^{22}$.

A terceira motivação é a natureza individual, muito associada ao poder de compra, que marca os avanços sociais recentes. Eles tiveram impacto econômico importante-e deveriam ser preservados, inclusive com a consolidação legal das politicas de transferência de renda e a rejeição da estratégia de aumento da competitividade às custas dos salários. Mas outro caminho para a promoção econômica e a redução da desigualdade foi pouco explorado: a infraestrutura social, os chamados bens de consumo coletivo ou público, como educação, saúde, transporte público e as condições de vida urbana, como o saneamento. Em várias dessas dimensões, a mercantilização progressiva foi a marca dos últimos anos. Permitiu-se uma ampliação do acesso a vários destes serviços, mas esta tendência descuidou dos aspectos de qualidade e conteúdo dos direitos sociais.

Ir além da ampliação do mercado de consumo de massas, avançando na dimensão dos direitos sociais (como, aliás, previsto na Constituição de 1988), é portanto a diretriz principal. Esta orientação também pode ser justificada pelo seu conteúdo moral e civilizatório, e seus impactos claros sobre a vida em sociedade e o bem-estar coletivo, mas o ponto a enfatizar aqui é seu potencial propriamente econômico.

Maiores investimentos nesta direção teriam efeitos multiplicadores importantes em termos de emprego, renda e atividades econômicas locais ${ }^{23}$. Além disso, a ampliação da renda disponível (resultante de uma ampliação no alcance e na qualidade dos serviços públicos) também seria um efeito econômico importante - não

22 Para um panorama ampliado dos indicadores de desigualdade no Brasil, ver DEDECCA, C. A redução da desigualdade e seus desafios. Ipea/IE-Unicamp, 2013. (mimeo)

23 Cálculos de Castro (2012) mostram que o efeito multiplicador em termos de renda e redução no Índice de Gini são muito maiores para gastos com saúde pública e educação, do que para pagamento de juros, construção civil ou de exportação de commodities. 
alcançado com a concessão de subsídios às empresas privadas prestadoras de serviços sociais, quase sempre com baixa qualidade.

Em outra frente, alterações na estrutura tributária na direção de uma maior progressividade também combinariam progressos econômicos e sociais. Complexo e concentrado em tributos indiretos (com baixa incidência sobre altos rendimentos e estoques de riqueza), a estrutura tributária é um mecanismo de concentração de renda e de riqueza no Brasil ${ }^{24}$. As dificuldades práticas e políticas envolvidas nesta tarefa não reduzem a sua importância para a construção de uma sociedade mais justa e com maior potencial de crescimento.

Em suma, pela leitura proposta, a grande questão econômica da Era Lula se relaciona com o potencial dinamizador de uma estratégia socialmente orientada, em uma versão adaptada (e muito atenuada) do sucesso europeu na era social-democrata. Mas esta lição não diz respeito apenas ao sucesso ou ao que foi conquistado. As dificuldades econômicas e políticas dos últimos dois ou três anos sinalizam que uma verdadeira sociedade civilizada (ou social-democrata) não pode ser construída apenas com base no consumo de massas, sem os outros elementos típicos e virtuosos dos arranjos sociais mais avançados. A prioridade para a melhoria dos serviços públicos e uma reforma tributária progressiva surgem, portanto, como as diretrizes mais adequadas para aprofundar e renovar o "social-desenvolvimentismo" esboçado, evitar o retorno a uma agenda liberal (ou uma busca a qualquer custo da competitividade) e retomar a o crescimento econômico.

24. Ver, novamente, os exercícios realizados por Castro (2012) para a quantificação dos efeitos da tributação sobre o Índice de Gini. 


\section{Sobre o autor:}

\section{André M. Biancarelli}

Professor do Instituto de Economia da Universidade Estadual de Campinas (IEUnicamp). Pesquisador do Centro de Estudos de Conjuntura e Política Econômica (Cecon/IE-Unicamp). Coordenador da Rede Desenvolvimentista.

E-mail: andremb@eco.unicamp.br 